\title{
Los tratados silogísticos de Boecio y su interdependencia temática
}

\author{
Manuel Correia \\ PONTIFICIA UNIVERSIDAD CATÓLICA DE CHILE
}

En los códices más antiguos y fidedignos, Boecio aparece como autor de dos tratados sobre silogística (que es la teoría lógica desarrollada por Aristóteles en sus Analíticos Primeros): la Introductio ad syllogismos categoricos (=ISC) y el De syllogismo categorico (=DSC) ${ }^{1}$. Estos tratados (el primero desarrollado en un solo libro y el segundo en dos) tienen una similitud notoria y por esta razón las primeras evaluaciones modernas determinaron una relación de dependencia entre ellos. Por ejemplo, no hace mucho tiempo, el connotado historiador de la lógica Prantl (1855), I, p. 682, no 80, creyó que la similitud entre ambos tratados era debida a que DSC era un extracto (excerpt) de ISC. Tal hipótesis mostraba un extremo de dependencia: Boecio en DSC había hecho un resumen de los contenidos de ISC. La única prueba de esta creencia era muy general, a saber, el que ISC aparece más amplio y completo que DSC en el tratamiento de sus contenidos. La apreciación de Prantl fue puesta en duda por Brandt (1903), p. 245, al observar más detenidamente que en ISC había una fuerte presencia de elementos que no están mencionados en DSC: los términos indefinidos. En efecto, estos elementos lógicos no forman parte de las proposiciones categóricas tratadas en DSC, pero en ISC son parte corriente del repertorio de ejemplos. Por otro lado, era evidente la presencia de silogística en el segundo libro de DSC y la absoluta carencia de un desarrollo sobre este tema en ISC.

Si bien la conjetura de Prantl fue desestimada por Brandt, la razón de por qué los tratados tenían similitud entre sí no había sido encontrada en absoluto. Fue así como pocos años después el italiano R. Murari en su obra Dante e Boezio (1905), p. 92, propuso una nueva hipótesis explicativa

1 Estos tratados han sido editados en J-P- Migne (1891). Sobre esta edición, ver J (2007), 131-132. Thomsen ThÖRnQvist (2008), 18. 
de esta relación: que el segundo libro de DSC (dedicado a la silogística) era la original continuación del único libro de ISC, mientras que el primer libro de DSC era espurio (y adosado a los códices en el medioevo). Esta creencia motivó en McKinlay (1907) la idea de poner a prueba la hipótesis del italiano por medio de métodos estilométricos que, a la vez, le permitirían relacionar la cuestión de la cronología de las obras de Boecio. Los resultados de la estilometría doblegaron el espíritu de McKinlay, quien llegó a confirmar la hipótesis de Murari e incluso ir, en su posterior trabajo de 1938, más allá que él, sosteniendo que el ISC conformado hipotéticamente por Murari (el único libro de ISC más el segundo libro de DSC) es, en realidad, la Institutio Categorica que Boecio menciona en su otro tratado De syllogismis hypotheticis $833 \mathrm{~B}$ y se tenía por perdida ${ }^{2}$.

Recientemente, ha aparecido una excelente edición crítica de ambos $\operatorname{tratados}^{3}$ (desde luego algo muy requerido) y su autora se ha visto naturalmente en la obligación de actualizar esta discusión y así ha encarado esta dificultad sosteniendo que en su opinión ISC alcanza a ser una revisión del primer libro de DSC, pues en el plan ISC es una revisión incompleta de todo DSC, no terminada por su autor. ${ }^{4}$ Esto abre la pregunta de si Boecio alguna vez escribió o pensó escribir un segundo libro para ISC, es decir, una revisión del segundo libro de DSC, a lo cual Thomsen Thörnqvist responde negativamente, siguiendo la impresión de Marenbon (2003), p. 49, de que Boecio al mismo tiempo que cesó su exposición en ISC se dio cuenta de haber ido demasiado lejos en lo que se supone no es más que una introducción a la teoría silogística de Aristóteles.

En este artículo voy a presentar una refutación a la tesis de MurariMcKinlay sobre la base de que ambos tratados tienen objetos temáticos diferentes entre sí, a pesar de las palmarias semejanzas que ofrecen a simple vista. Empero, las razones por las cuales fundamento esta diferencia me llevan a modificar parcialmente las opiniones de Thomsen Thörnqvist y Marenbon en el sentido de que, más que una revisión, ISC es un apéndice a DSC, es decir, un tratado que busca complementar directamente la teoría de la conversión e indirectamente la del silogismo desarrolladas en

2 McKinlay (1938), 218. Una discusión más detallada de esta hipótesis en Correia (2007), 131-138.

3 Thomsen Thörnqvist (2008) y (2008a).

4 Thomsen Thörnqvist (2008), xxxix. 
DSC, asunto que ISC realiza al incorporar las diferencias fundamentales que experimentan las operaciones de conversión y conversión por contraposición cuando los términos que componen las proposiciones son indefinidos.

\section{Terminología y doctrina de los tratados}

La similitud de DSC e ISC se debe a que ambos tratados comienzan con un sumario de la porción lingǘstica del comentario al De Interpretatione de Aristóteles hecho en dos ediciones por Boecio $(=\text { in Int })^{5}$. El paralelo entre ambos tratados es casi exacto en lo que respecta a las definiciones de nombre, verbo, frase, nombre indefinido, verbo indefinido, casos del nombre, etc. Desde un punto de vista terminológico, las exposiciones de los dos tratados son casi iguales. No obstante, una profundización en el análisis encuentra la diferencia central: solo ISC adopta la estrategia explicativa de in Int de distinguir entre definiciones estrictas y no estrictas de los elementos de la proposición categórica. DSC no dice nada en este respecto y tampoco usa ni siquiera implícitamente este instrumento exegético. Una definición estricta de nombre deja fuera a los nombres indefinidos (elementos como 'no-hombre', 'no-blanco'), porque no significan, como los nombres simples, una sola cosa, pero bajo la definición no estricta cabe definirlos como nombres, ya que son sonidos articulados, sin tiempo, que significan por convención y ninguna de sus partes significa en separación. Esta diferencia terminológica es una señal clara de que el primer libro de DSC proviene de la misma enseñanza tradicional que ISC (que seguramente se entronca a la línea de comentarios al De Interpretatione de Aristóteles), pero el uso de esta información es desde luego más superficial en DSC. Esto coincide con la apreciación recogida por Thomsen Thörnqvist 2008a, p. xix, hecha antes por De Rijk (1964), pp. 10-23, de que DSC es un trabajo temprano en el que la terminología lógica de Boecio está todavía en un estado experimental y que incluso había sido notada ya por McKinlay, quien consideró el lenguaje del primer libro anormal e incluso como espurio ${ }^{6}$.

La consideración de este aspecto terminológico, que no es menor, conduce a creer merecidamente la misma opinión de Thomsen Thörnqvist

5 Este comentario, que citaremos como in Int (si es el primer comentario) e in Int 2 (si es el segundo comentario), tiene su edición crítica en Meiser (1877-1880).

6 McKinlay (1905), p. 144. Ver también McKinlay (1938), 213. 
de que ISC es una revisión del primer libro de DSC. No obstante, me parece que esto no puede sostenerse de la misma manera por las consecuencias que se siguen de esta nueva hipótesis. Si suponemos que Boecio decidió revisar el primer libro de DSC y que el producto de esta revisión es ISC, tendremos que explicar qué papel cumplen en silogística los términos indefinidos, asunto este que ha quedado expuesto a una pura especulación sin mayor base textual en la historia de la lógica. Y es que no hay ninguna noticia ni directa ni indirecta que aluda siquiera a la existencia de una extensión de la silogística sobre la base de la incorporación de términos indefinidos en las premisas de los modos válidos de las tres primeras figuras silogísticas y los modos indirectos de la primera. No sabemos que Teofrasto o algún otro peripatético antiguo haya planteado esto alguna vez ${ }^{7}$. Los intentos conocidos en este particular son todos nacientes en el siglo XX gracias a los trabajos de A. Prior, I.M. Bochenski e I. Thomas y están inspirados más en una cuestión lógica que histórica ${ }^{8}$. Esta situación es la que, a mi modo de ver, lleva a Thomsen Thörnqvist (2008a), p. xviii, a conciliar su hipótesis con la de Marenbon (2003) de que ISC termina abruptamente, sin decir nada sobre silogística, porque Boecio se dio cuenta de que había llegado demasiado lejos con la incorporación de los términos indefinidos en ISC y decidió cesar su trabajo de modo que el segundo libro de este tratado jamás lo escribió. Mi opinión es que este segundo libro jamás podría haber sido escrito y, más aún, jamás siquiera se concibió, porque concebirlo significa incorporar elementos que no tendrían ninguna utilidad a la teoría silogística, ya que no hay evidencia textual sobre cómo esta teoría es consistente al incorporar términos indefinidos en las premisas de los modos silogísticos válidos, ni cuántos modos válidos hay, ni si pueden ser deducidos desde los cuatro primeros y perfectos que, según Boecio, Aristóteles utilizó para determinar todos los modos válidos en las tres figuras silogísticas?. Tal extensión, si la hubo, es una ínfima parte de lo que hay que tratar ${ }^{10}$. En estas circunstancias, creo que la posición más sana es sostener que ISC no puede ser una sola

7 Apuleyo en su Peri Hermeneias y Boecio en DSC consignan ciertas extensiones a la silogística: los cinco modos indirectos de la primera figura y un otro Darapti en la tercera. Apuleyo adscribe a Teofrasto, además, el uso de premisas singulares, lo cual tampoco se ve en Aristóteles. Sin embargo, no se aprecia en ninguno de estos tratados antiguos el uso de premisas con términos indefinidos.

8 Cf. Prior (1953), pp. 1-6. Bochenski (1948), 35-37. Y Thomas (1949), 145-160.

9 Cf. DSC 823A1-10.

10 Cf. más adelante $n^{\circ} 26$. 
revisión de DSC y hay que abrirse, consiguientemente, a la posibilidad de que DSC e ISC sean tratados más diferentes entre sí de lo que hasta aquí se había supuesto, a pesar de la obvia yuxtaposición de contenidos que se aprecia entre el primer libro de DSC y el desarrollo de ISC. Esta posición que sostengo se ve confirmada por la siguiente observación.

\section{La división programática de DSC e ISC}

Luego del desarrollo de la parte lingüística del De Interpretatione de Aristóteles, el cual se resume en un estudio de los elementos de la proposición categórica (nombre, verbo, etc.), en los dos tratados proviene una división de la proposición categórica que es de sumo interés para confirmar la hipótesis de la diferencia entre ambos tratados. De hecho, la estructura expositiva que esta división forma en los tratados es causa de que los autores también hayan concedido la tesis de la dependencia entre ellos, pero una revisión más profunda de estas divisiones muestra que ambos tratados son diferentes como diferentes son también las divisiones al interior de cada uno de ellos. En ambos tratados, la división de la proposición categórica es destinada a ver si, tomadas dos proposiciones y puestas en comparación una con otra, se halla uno o ambos términos en común, ya en el mismo orden ya en uno distinto. Proposiciones como "la virtud es buena" y "el hombre es blanco" no tienen términos en común. La diferencia no es insignificante, pues el origen de la teoría lógica está en juego, ya que las proposiciones que no tienen ni siquiera un término en común no pueden ser estudiadas por la lógica, aunque sí todas las otras que tienen uno o los dos términos en común, en cualquier orden.

Por medio de esta división, DSC logra conectar tres temas centrales a la lógica aristotélica: (i) la semántica del cuadrado de las oposiciones ${ }^{11}$, (ii)

11 Esta pieza de comentario, que sigue la división establecida, se hace con magistral lucidez y con extrema precisión. Al tratamiento característico hecho por Aristóteles de las contrarias, contradictorias y subalternas, Boecio introduce la de las subalternas. Este es el primer texto latino que posee esta enseñanza. Establece DSC que si la Universal Afirmativa (que llamaremos aquí A por comodidad) es verdadera, la Particular Afirmativa $(=\mathrm{I})$ es verdadera también. Lo mismo entre la Universal Negativa $(=\mathrm{E})$ y la Particular Negativa $(=\mathrm{O})$. Y agrega que esto no es válido viceversa, es decir, desde las particulares a las universales. Interesantemente, agrega que si las universales son falsas, no se puede establecer la verdad o falsedad de las particulares, pero que si las particulares, ya sean afirmativas o negativas, son falsas, la universales lo serán también. Se puede decir que el DSC tiene la primera revisión completa del cuadrado de las oposiciones, es decir, tan completa como aparece actualmente en los libros de 
la teoría de la conversión ${ }^{12}$ y (iii) la teoría silogística ${ }^{13}$. En efecto, luego de comentar sobre el nombre, el verbo, los nombres y verbos indefinidos, los casos del nombre y del verbo; sobre la frase u oración y finalmente sobre la proposición, Boecio divide las proposiciones en aquellas cuyos términos (a) nada tienen en común entre sí de aquellas que (b) algo tienen en común entre sí. Ejemplos de (a) son 'todo hombre es animal' y 'la virtud es buena', pues estas dos proposiciones no tienen ningún término en común. En cuanto a (b), las proposiciones que tienen algún término en común pueden o bien (b.1) tener ambos términos en común o bien (b.2) tener algún término en común. En (b.1) encontramos dos tipos: (b.1.1) según el mismo orden y (b.1.2) según un cambio de orden. Ejemplos de (b.1.1) son: 'todo hombre es animal' y 'ningún hombre es animal', pues estas dos proposiciones tienen el sujeto y el predicado en común (es decir, ambos términos) y su orden no varía. Pero como varía la cantidad o la calidad de las proposiciones, la teoría semántica del cuadrado de las oposiciones y la teoría de la conversión se generan y operan con este tipo de proposiciones. Por su parte, ejemplos de (b.1.2) son: 'todo hombre es

lógica que enseñan esta teoría sobre las relaciones semánticas entre proposiciones categóricas.

12 Aquí nuevamente encontramos una pieza de notables aciertos. La conversión es dividida en simple y por contraposición. La conversión simple es la enseñada por Aristóteles en Analiticos Primeros y conserva todos sus resultados, pero, como mostraré en seguida, se teoriza sobre ella más ampliamente que en Aristóteles. Luego, se trata de la conversión por accidente (per accidens), que se define como aquella entre la $\mathrm{A}$ y la I, y entre la E y la O. Hay una clara conciencia de que la validez de la conversión depende de la extensión de los términos y de la materia de las proposiciones. Por ello es que Boecio distingue entre las conversiones que son válidas por la materia de la proposición y las que son válidas universalmente, o sea, que no dependen de la materia. El punto es, desde luego, notable, no solo porque se aclara cuáles son las conversiones válidas, sino porque Boecio aclara qué es una verdad formalmente válida: a saber, cuando las proposiciones son convertidas en todos los casos (805B11).

13 Parece bien probable que Boecio está siguiendo en DSC una cierta Introducción a los Silogismos Categóricos que Porfirio, o algún autor de su entorno, habría escrito para evaluar y aprobar la teoría silogística de Teofrasto y Eudemo. (Cf. 829D5). Ahora bien, la teoría que Teofrasto desarrolla es una extensión conservadora de la teoría silogística de Aristóteles, es decir, una que sigue las mismas reglas silogísticas que Aristóteles usa en sus Analíticos Primeros para determinar 14 modos válidos en tres diferentes figuras. Sin embargo, Teofrasto descubre los así llamados 'indirectos', a saber, Baralipton, Celantes, Dabitis, Fapesmo y Frisesomorum, y los agrega a los modos de la primera figura. Notablemente, aun cuando es posible hacerlo, Teofrasto no intenta extender los modos silogísticos de todas las figuras distinguidas por Aristóteles, sino solo los de la primera. Cf. no 28 y n 29 . 
animal', 'todo animal es hombre', pues estas proposiciones tienen los dos términos en común, pero no conservan el mismo orden. Este es el tipo de proposición que estudia la teoría de la conversión. En cuanto a (b.2), o sea, proposiciones que tienen algún término en común, hay tres especies: (b.2.1) aquellas que tienen el término común en el sujeto (la primera) y en el predicado (la segunda); y (b.2.2) aquellas que lo tienen en el predicado en ambas; y (b.2.3) aquellas que lo tienen en el sujeto en ambas. Desde estas tres últimas especies surgen las tres figuras silogísticas, como se ve en los siguientes ejemplos correspondientes: 'todo hombre es mortal' y 'todo griego es hombre' $\left(=1^{\mathrm{a}}\right)$; 'todo hombre es mortal' y 'todo animal es mortal' $\left(=2^{\mathrm{a}}\right)$; 'todo hombre es animal' y 'todo hombre es griego' $\left(=3^{\mathrm{a}}\right)$.

La división de ISC, por el contrario, no es tan completa como la de DSC al no incorporar la teoría de los silogismos, pero es más específica que la de DSC, al incorporar los términos infinitos. En la siguiente descripción se ve la relación de superposición que hay entre las divisiones de los tratados silogísticos, la cual permite ver cuál es la similitud y diferencia entre estos dos tratados:

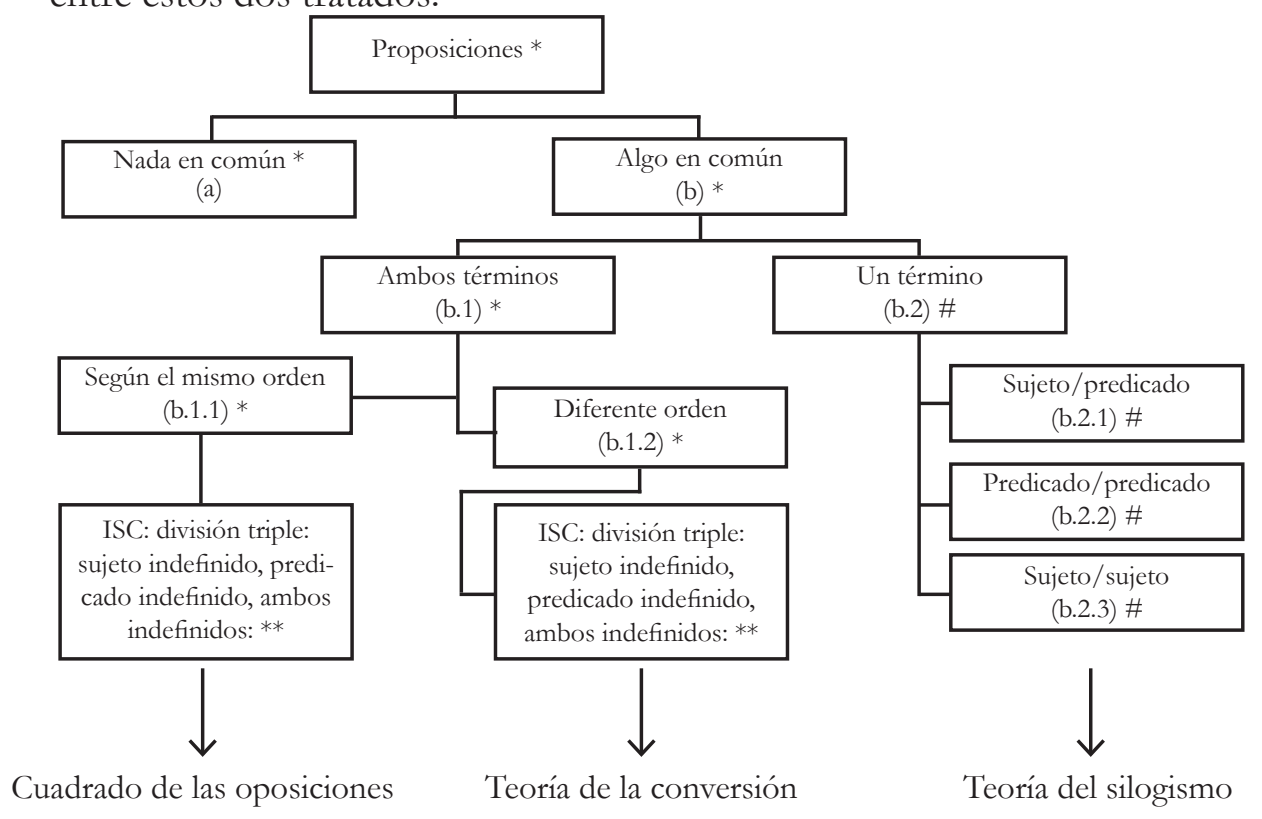

\footnotetext{
* : común entre DSC e ISC.

\# : solo en DSC

**: solo en ISC
} 
DSC incluye la variación de orden que tiene un término común en un par de proposiciones simples. Es el orden del término medio en la teoría del silogismo de Aristóteles ${ }^{14}$. Pero ISC no se enfoca en esta distinción, lo cual no quiere decir que la ignore, sino que pone interés en las proposiciones que tienen dos términos en común y entonces pueden variar solo en lo que respecta a su orden de sujeto y predicado o de conversión.

La gran diferencia existente entre estas divisiones hace imposible la hipótesis de Murari-McKinlay. En efecto, estos investigadores llegaron a creer que ISC era el verdadero primer libro de DSC, pero esto es imposible porque las divisiones de la proposición categórica ofrecidas por ISC y DSC no son exactamente congruentes. Hay similitudes, desde luego: son ambas divisiones muy generales y ambas comparten la primera división (proposiciones con términos en común/sin términos en común). No obstante, la de DSC es, como decimos, más amplia que la de ISC, aunque la de ISC más específica que la de DSC. En efecto, tanto DSC como ISC dividen las proposiciones que tienen un término en común en (i) ambos términos en común y (ii) un solo término en común. Pero, ISC olvida (o tal vez deja latente) que los términos que son comunes no son siempre dos, sino que también solo uno puede ser común a dos proposiciones simples. Con lo cual deja latente la teoría del silogismo. Es entonces cuando ISC entrega lo propio y específico de su objeto temático al indicar que cuando ambos términos son comunes a dos proposiciones, ellos pueden ser definidos o indefinidos. Ahora bien, al suponer, como lo hace esta hipótesis, que ISC es el primer libro de DSC ocurre la dificultad de qué hacer con los términos indefinidos, ya que ellos no son utilizados en ningún momento en los silogismos, es decir, en el segundo libro. La cuestión es similar a incluir elementos que después resultan sin utilidad. Tal como si el autor de un texto incorporara en el primero de dos libros un ingrediente que después ignora.

Conviene notar que de acuerdo con la Editio Princeps de 1492 y el códice

${ }_{14}$ Con todo, DSC no se abre a la posibilidad de contar una cuarta posibilidad b.2.4 Predicado/sujeto, lo que daría lugar a una cuarta figura silogística. DSC como todos los tratados antiguos de silogística es escueto en cuanto a justificar por qué no hay una cuarta figura silogística. Sin duda, esto se debe al silencio de Aristóteles en este sentido. Cf. DSC 810D14-811 A 1. Tribus igitur terminis ita positis, ut prope se et sibi connexi sint, tres non ultra fieri complexiones necesse est hoc modo. 
Vaticano 1722 del siglo XII, la mención de Boecio en ISC 787D1 es de que la obra es una instrucción (instructio) para los silogismos categóricos, no una introducción (institutio), pero la ocurrencia de institutio dos veces antes en el texto (761B1 y 762C9) decidió naturalmente a Thomsen Thörnqvist a adoptar institutio. Esta alusión -por cierto tardía al propósito de la obraes importante porque es aquella donde Boecio dice más directamente que se trata de un trabajo sobre los silogismos categóricos. Mi hipótesis es que la propuesta de ISC es hacer una instrucción como se lee en la editio princeps, que complemente la tarea silogística como una explicación general sobre el uso de términos indefinidos en las premisas que por conversión han llegado a formar un modo silogístico. Esto explica por qué es necesario repetir muchos de los contenidos de DSC sin que las obras, por ello, sean iguales o una un resumen de la otra.

Así, esta mención que se hace tardíamente después de la alusión del proemio del tratado y sin que el lector la haya necesitado o la necesite, confirma que ISC no tiene por objeto temático hacer una introducción a la silogística, sino una exposición sobre lo que puede aportar a ella, a saber, las diferencias que ocurren al oponer y convertir las proposiciones cuando estas son sistemáticamente consideradas como conteniendo términos definidos o indefinidos. El texto de Boecio dice:

«Sed quamquam huiusmodi participationis plures esse differentias nouerimus, ad institutionem/ad instructionem ${ }^{15}$ tamen categoricum syllogismorum de hac tantum propuisse sufficiat.»

«Sin embargo, aunque hemos conocido que son muchas las diferencias de la participación $<_{\mathrm{o}}$ sea, de $b$ ) en la división expuesta arriba $>$, es suficiente haber propuesto solo estas para proveer información acerca de los silogismos categóricos.»

Y agrega inmediatamente a continuación:

«Quarum quidem propositionum pars ex simplicibus nominibus constat, pars vero ex infinitis, nam propositio universalis, quae est omnis homo animal est, ex utrisque finitis nominibus constat (namque homo et animal finita nomina esse manifestum esse), ea vero affirmatio quae proponit omne non animal non hominem esse, ex infinitorum terminorum positione coniuncta est (non animal enim et non homo nomina esse infinita in nominis deffinitione praediximus).»

15 La lectio ad institutionem en Thomsen Thörnqvist (2008a, p. 71). La Editio princeps y el códice Vaticano 1722 poseen la expresión ad instructionem. 
«Pues, una parte de las proposiciones consta de nombres simples, la otra, empero de nombres indefinidos, pues la proposición universal 'Todo hombre es un animal' consta de ambos nombres simples (pues es evidente que 'hombre' y 'animal' son nombres definidos), pero la afirmación que propone 'Todo no animal es un no hombre' es conformado por la posición conjunta de nombres indefinidos (pues en la definición de nombre llamamos a 'no animal' y 'no hombre' ser nombres indefinidos).»

Así, los mismos textos dan pie para interpretar que la evidencia de que ISC es un tratado más prolijo, extenso y profundo en sus comentarios que los de DSC, compartida por todos los que han investigado la relación entre estos dos tratados sobre silogística categórica, se explica porque ISC tiene por objetivo servir de complemento a DSC, que a su vez, transcribe una introducción a la silogística aristotélica tanto como a la sazón era posible. Y para ello ISC ofrece una justificación más acabada de las inferencias lógicas que, ya sea por oposición (el cuadrado de las oposiciones) o por conversión (conversión simple y por contraposición), se requieren para el desarrollo de la teoría silogística.

\section{La independencia de los tratados}

Todo lo anterior se suma a la causa de que hay que modificar lo sostenido por Thomsen Thörnqvist en su comentario a los tratados: ISC no puede ser una revisión del primer libro de DSC, porque si se hubiere escrito con este fin, se desvirtuaría al mismo tiempo el proyecto: si los términos indefinidos no van a ser incluidos en las premisas de los silogismos categóricos, ¿para qué ocupar tiempo en la explicación de ellos? ISC tiene por objetivo general el relacionar términos indefinidos, proposiciones categóricas y teoría silogística, pero lo que la doctrina silogística de Aristóteles puede aceptar, en este sentido, no es más que indirecto y es la sustitución de un término simple por uno indefinido, en una premisa de un silogismo, si el término simple puede generar el indefinido a través de la conversión y sobre todo la conversión por contraposición, pues ni en DSC ni en ISC se enseña cómo operar lógicamente con términos indefinidos al interior de un silogismo, ni se suministran reglas para este fin. Así, como ya dijimos, lo que ISC presenta es un estudio más pormenorizado, conforme a la división programática, sobre inferencias con nombres indefinidos, cuando las proposiciones que van a ser convertidas están compuestas por un sujeto indefinido o un 
predicado indefinido.

La profundización de sus contenidos se puede apreciar no solo en cuanto a la variación o diferencia lógica que incorporan los nombres indefinidos al formar parte de las proposiciones categóricas, especialmente cuando estas se convierten y se contraponen entre sí, sino también en el intento por hacer uso, de manera más sistemática que en DSC, de la doctrina de los predicables para definir cuando una inferencia lógica es correcta o universalmente válida. Entre los comentaristas más antiguos de la lógica de Aristóteles, Apuleyo ${ }^{16}$ y Alejandro de Afrodisia ${ }^{17}$, y luego en otros posteriores, como Porfirio ${ }^{18}$, Amonio ${ }^{19}$ y desde luego Boecio, tanto en ISC como en $\mathrm{DSC}^{20}$, existe un procedimiento de prueba diseñado para calcular la validez de las inferencias y equipolencias definidas por Aristóteles, que se basa en la doctrina de la materia de la proposición (según la denominación que ocupan algunos autores tardíos como Amonio) o la doctrina de las significaciones (significationes), tal como la menciona Apuleyo. Consiste en tomar el predicado de una proposición y reemplazarlo de manera que las predicaciones que se produzcan, teniendo la misma forma, recorran todas las significaciones y contenidos pensables o imaginables. Lo que se busca es la forma de la proposición y la doctrina de la materia de la proposición viene en auxilio en este punto al sostener que estas significaciones no son infinitas, sino que, como aclara puntualmente Apuleyo, son solo cinco ${ }^{21}$ : el género, la definición, la propiedad, el accidente y la esencia. Las cinco significaciones coinciden con los predicables mencionados por Aristóteles en los Tópicos (101b37 y ss.) y sin duda son un acercamiento al tema de cuántas son todas las maneras en que el predicado de una proposición categórica se relaciona con el sujeto. Así, de acuerdo con este método de prueba, una conversión por contraposición (por ejemplo, “todos los hombres son animales, por tanto todos los no animales son no hombres”) es válida lógicamente si, consideradas todas las materias ${ }^{22}$, las que hacen verdadero el antecedente

16 Peri Hermeneias VI, 4-6, 182.

17 In Top 192. 4-10; 10, 19-24. (= Wallies 1891).

18 Porfirio es citado por Boecio. Ver no 20.

19 Amonio in Int, p. 88, 12-23. (= Busse 1895).

20 De syllogismo categorico 804A8; 805B1-805C1; 808B2 y ss. (= Migne 1891).

21 Peri Hermeneias p. 182,6 (= Thomas 1908).

22 Si se verificara en algunos casos solamente, entonces habría una verdad material, no formal. 
hacen también verdadero el consecuente y si, a su vez, las que hacen falso el antecedente así también hacen el consecuente ${ }^{23}$.

Con todo, la intención de Boecio no debe ser extendida más allá, pues en ISC Boecio no es consciente de todas las dificultades que estas operaciones lógicas incorporan una vez que sus términos son indistintamente definidos e indefinidos ${ }^{24}$. Y, lo más importante, no hay ningún indicio, un solo ejemplo, de qué sería un silogismo con términos indefinidos en sus premisas y cuáles principios gobernarían su validez. La deuda de ISC es explicar cuál es la relación que la lógica de los términos indefinidos tiene con la silogística en las investigaciones lógicas de Aristóteles.

Más bien parece haber lugar para proponer que ISC no es el primer libro de DSC ni una revisión suya, sino que una obra independiente, esto es, que su objeto temático no es el mismo que DSC. En el primer tratado, la relación con la teoría silogística es indirecta y referida solo por el título y la breve indicación de que se viene una revisión de la conexión (conexio) entre lo tratado y la silogística, pero la silogística no está consignada en la división programática del tratado. De acuerdo son esto, dice Boecio en 762D1:

Pero dejemos este asunto hasta aquí. Ahora seremos guiados por el tema propuesto. En efecto, puesto que esta obra para nosotros es acerca de los silogismos categóricos, pero la composición de los silogismos se hace a partir de las proposiciones y las partes de la proposición son el nombre y el verbo, resulta que lo primero es la parte de aquello de que es parte. Así la primera discusión que se propone es acerca del nombre y del verbo, que son las primeras cosas, después acerca de la proposición y al final se tratará de su conexión con los silogismos (debinc de propositione atque ad ultimum de syllogismorum conexione tractabitur).

23 Naturalmente, la lógica puede ocuparse también de los casos en que la inferencia es válida en algunas materias y no en todas, identificando cuáles son esas materias según el tipo de consecuencia o equipolencia en cuestión, pero con propiedad la lógica no define una verdad formalmente válida a no ser que la fórmula se verifique en todas las materias o predicables.

24 Estas dificultades fueron vistas por algunos lógicos medievales posteriores (por ejemplo, John Buridan) y todas apuntan a una incompatibilidad con la así llamada cuestión del importe existencial. Ver más detalle en la discusión de Terence Parsons para "The Traditional Square of Opposition", en la Stanford Encyclopedia of Philosophy, (http://plato.stanford.edu/entries/square/), 2006. Contiene bibliografía. 
En cambio, en DSC se dan ambas condiciones: el tema es sugerido por la expresión del autor y desde luego la diferencia correspondiente está consignada en la división programática. Si los tratados fueran independientes, DSC sería la verdadera introducción a los silogismos categóricos que provenía desde la tradición peripatética acogida por la escuela neoplatónica de Porfirio ${ }^{25}$ e ISC debería ser una suerte de tratado independiente, cuya finalidad y objeto temático o no están bien definidos o consisten, como he sugerido antes, en servir de apoyo a la silogística.

Pero el que los tratados sean independientes permite la entrada de otras dificultades que hay que despejar. La primera es la reconsideración de la tesis de Usener 1880, p. 369, luego reformulada por Shiel (1958), p. 238, de que ISC es el breviarium del comentario que Boecio hizo en dos ediciones al De Interpretatione de Aristóteles y prometido en este comentario (in Int 2, p. 251, 8-9). La refutación de esta hipótesis de Usener y su reformulación en Shiel ya fue hecha por De Rijk (1964), pp. 37-38. Las razones dadas por De Rijk son (i) que tanto DSC como ISC (este tratado al menos en su título y expresión introductoria del autor) son obras sobre los silogismos categóricos y no solo sobre las doctrinas del De Interpretatione. Además, (ii) la doctrina de la materia de la proposición que es parte corriente de los dos tratados no aparece en el comentario al De Interpretatione. A estas dos objeciones cabe agregar también el que la conversión y la conversión por contraposición no son temas tratados en el doble comentario al De Interpretatione y entonces no podría ser ISC (Usener) o ISC más DSC (Shiel) el breviarium prometido. Definitivamente entonces ni ISC ni DSC más ISC son el breviarium en cuestión.

La pregunta que se abre así es qué puede ser ISC. ISC incorpora correctamente un estudio sobre los términos indefinidos; con esto amplía la división y el conocimiento de la lógica (que debió ser el objetivo del trabajo de Boecio); la pregunta que se abre es por qué, a diferencia de ISC, el primer libro de DSC no toca la distinción del término en simple e indefinido (incluso por qué no se usa el paradigma explicativo de una definición más estricta y otra menos estricta del nombre). Murari y McKinlay, en cierto modo, trataron de contestar a esta cuestión al decir que el segundo libro de DSC es la continuación de ISC. Pero esta conjetura es imposible de acuerdo a nuestra perspectiva. Thomsen Thörnqvist cree actualmente que ISC es una revisión del primer libro de DSC. Mi propio convencimiento es que ISC no es tanto una introducción a la ${ }^{25}$ Cf. $\mathrm{n}^{\mathrm{o}} 28 \mathrm{y} \mathrm{n}{ }^{\circ} 29$. 
silogística categórica sino una doctrina para ella, una instructio, que aunque no busca mostrar la diferencia conclusiva de la silogística al incorporar de distinto modo los términos indefinidos, sí prepara a los que van a convertir proposiciones con términos definidos (tal como en DSC) como indefinidos (tal como se agregan en ISC) para eventualmente usar esas premisas en silogismos.

En todas estas apreciaciones, DSC ha quedado supuesto como una obra con clara unidad de objeto, a pesar de la relativa falta de forma del latín de su autor, especialmente del libro primero. Esta unidad es brindada por la división central que comentamos arriba. Y, en consecuencia, DSC e ISC son tratados enteramente distintos en cuanto a sus objetos temáticos y en cuanto a lo que buscan desarrollar siguiendo la división central de la proposición según tenga esta un término en común con otra o no. DSC es un tratado unitario cuya finalidad es entregar un resumen de la lógica aristotélica tal como se encuentra desarrollada en los primeros siglos de nuestra era. ISC, por su parte, es un tratado sobre la proposición categórica y sus componentes, que entrega una teoría más completa sobre la proposición categórica, incluyendo las indefinidas, con vistas a la teoría de la conversión de las proposiciones y, aunque no se relaciona con la silogística aristotélica de modo significativo, promete estudiar la relación. Esto otorga una intención original del autor. Así, me parece que un aspecto que no hay que olvidar en la apreciación de ISC es que el tratado ofrece un aditamento a lo ofrecido por la introducción a los silogismos categóricos que Boecio representó en su extensión teórica en el latín de DSC: esto justificaría repetir algunos contenidos ya suficientemente claros en su primera explicación.

La hipótesis de Thomsen Thörnqvist (2008) y (2008a), avalada por la creencia de Marenbon (2003), apunta a concebir ISC como la segunda edición de DSC y, por tanto, indica que Boecio para sus tratados sobre silogística mantuvo el mismo modus operandi que en sus comentarios, a saber, hacer una doble aproximación al material griego en cuestión para lograr entender más a fondo las doctrinas de los comentaristas. Así procedió Boecio de hecho, realizando un doble comentario a la Isagoge de Porfirio, a las Categorías y al De Interpretatione de Aristóteles: traduciendo primero todo lo que era más evidente a su comprensión, dejando para un segundo comentario lo más difícil y oscuro de entender. La hipótesis de Thomsen Thörnqvist funciona bien si es que los tratados silogísticos son traducciones del griego. Si lo fueran (y no tengo reparos a que lo 
sean), nos encontramos con el verdadero escollo de esta hipótesis, que es -como hemos argumentado- el que deberíamos suponer que Boecio en este material tuvo ante su vista ejemplos de usos de términos indefinidos en silogística. Y esta suposición, como dijimos, no tiene ninguna base textual. La única que podría citarse, viene a probar que la tradición peripatética antigua no tuvo un desarrollo significativo en este respecto. El mismo Boecio recuenta en su segundo comentario al De Interpretatione (in Int 2, 12-26, p. 316) que, según Alejandro de Afrodisia, Platón y otros autores hicieron silogismos conclusivos con premisas negativas, lo cual Aristóteles prohíbe en Analíticos Primeros I, 4.41b7-9. Según el reporte de Boecio, esto es posible (y confirma la regla de Aristóteles de que no hay silogismos conclusivos con premisas negativas), porque Platón sabía que una proposición categórica negativa, a veces, puede ser sustituida por la respectiva afirmación con predicado indefinido. El ejemplo, según el reporte, se encuentra en Teeteto (186e3-4), donde Platón dice que quien no capta el ser tampoco capta la verdad. Y quien no capta la verdad no puede tener conocimiento. De donde se concluye que quien no capta el ser tampoco tiene conocimiento. Este silogismo y otro que Aristóteles desarrolla en De caelo 269b29-31 son los únicos que pueden ejemplificar el capítulo de la lógica antigua donde se desarrollan silogismos con términos indefinidos ${ }^{26}$. El ejemplo monográfico permite creer que esta es la sola enseñanza que al respecto la lógica antigua puede atestiguar. Pero la pregunta crucial de si el segundo libro de ISC contenía un análisis más a fondo de este caso reportado por Boecio en su comentario al De Interpretatione no puede ser confirmado por falta de más información.

Thomsen Thörnqvist (2008a), p. xix, tiene que argumentar que el segundo libro de DSC no tenía tanta necesidad de ser revisado como el primero y que, por tanto, el segundo libro de ISC tendría, de haber sido revisado, el mismo límite teórico que el segundo libro de DSC, esto es, una exposición de la silogística de Aristóteles y de las extensiones de Teofrasto y Eudemo mencionadas alli $i^{27}$. Pero, según el argumento natural, debería haber necesidad de revisar el segundo libro de DSC por cuanto la relación que promete ISC va dirigida específicamente al uso de términos indefinidos en las premisas silogísticas y esto, salvo la excepción del Teeteto de Platón, reportada por Boecio siguiendo la noticia del peripatético Alejandro de Afrodisia, no tiene ninguna otra fuente textual en la literatura

26 Mayor información sobre este punto en Correia (2001), 161-173.

27 Cf. DSC 813B12, 814C6, 814D y ss. 829D5. 
antigua. Así, existiendo este escollo a la hipótesis de Thomsen Thörnqvist, me ha parecido importante proponer una explicación alternativa: tanto DSC como ISC son tratados que están suficientemente completos desde el punto de vista doctrinal. ISC es un tratado que está escrito para servir de ayuda a DSC, completando las doctrinas de la inferencia lógica (por oposición y conversión) con la incorporación de los términos indefinidos, que no habían sido incluidos en DSC, con el fin de que la teoría silogística no carezca de un estudio sobre la incorporación de premisas con términos indefinidos.

Mi propuesta de explicación puede ser criticada por el hecho de que en ISC Boecio no dice nunca nada sobre DSC, ni lo menciona en absoluto. Pues, en efecto, sería natural que lo hiciera si, como decimos, ISC está haciendo un aporte a DSC. Mi defensa en este punto remite al hecho de que ISC tampoco menciona al DSC como una revisión suya, ni de otro modo en absoluto y, desde luego, también sería razonable que lo hiciera. Si vamos a los textos mismos, Boecio dice en DSC estar tomando los contenidos desde una introducción a los silogismos categóricos ${ }^{28}$. A partir de aquí, se hace sostenible la creencia de que DSC sea la verdadera introducción a los silogismos categóricos de la tradición peripatética, adoptada bajo el mismo título por Porfirio ${ }^{29}$. Si, por su parte, ISC dice ser una instrucción (instructio) a los silogismos categóricos, se puede más fácilmente entender que Boecio esté traduciendo material instructivo para la tradicional introducción a los silogismos categóricos que Boecio tuvo a su disposición. En tal caso, podríamos decir que ISC menciona a DSC de manera elíptica. Si, en cambio, llamamos a ISC una "introducción a los silogismos categóricos" no permitimos que se establezca una relación de utilidad entre DSC e ISC y, más aún, no sabríamos a cuál de los dos

28 DSC 829D5 y ss. "Y estas cosas las extraje desde una Introducción a los Silogismos Categóricos, siguiendo a Aristóteles mayormente, y tomando prestado algunas cosas de Teofrasto y Porfirio, tanto cuanto la brevedad de una introducción me lo permitía”.

29 Hay suficiente evidencia sobre la redacción de una Introducción a los silogismos categóricos hecha por Porfirio. La frase de Boecio en DSC 829D5 [Haec de Categoricum Syllogismorum introductione (...) expressi.] puede ser tomada como un signo del título correcto de DSC. En primer lugar, VAN DE VYVER (1929), 444, ha observado que DSC en los más antiguos manuscritos se titula Introductio in categoricos syllogismos y este título concuerda con el título de un tratado similar atribuido a Porfirio (cf. BIDEz 1964, 66*). Cf. también De Rijk 1964, p. 39 y p. 162. Y. Magee 1998, 5, nº 10. Y, McKinlaY 1907, 143, no 1. También M. Paluello 1972, 328. Cf. Correia (2009), vol. 2, no 2. Cf. también atrás $n^{\circ} 13$. 
tratados llamar una introducción. Si vamos a la división central de cada uno de los tratados, no hay razón para sugerir que ISC sea propiamente una introducción a los silogismos, ya que, a diferencia de DSC, no destaca las figuras silogísticas en la división. En consecuencia, no me parece que la objeción de que ISC no menciona a DSC sea más nociva para mi hipótesis que para la de Thomsen Thörnqvist y, consiguientemente, nuestra hipótesis de que ISC es un tratado cuya función es servir de apoyo a DSC parece ganar aún mayor validez explicativa ${ }^{30}$.

\section{Resumen}

En este artículo se discuten las más importantes hipótesis modernas que han intentado explicar la interrelación doctrinal que los tratados silogísticos escritos por Boecio tienen entre sí, el De syllogismo categorico y la Introductio ad syllogismos categoricos. Se revisan las hipótesis que señalan una dependencia fuerte entre ambos tratados y también las que apuntan hacia una dependencia más débil y, luego de criticar estas posiciones, la discusión abre la posibilidad cierta de que los tratados tengan objetos temáticos diferentes y estén relacionados de una manera más extrínseca que lo que se había creído hasta aquí, ya que el segundo de ellos estaría pensado como un complemento al primero. El argumento se basa tanto en la manifiesta falta de utilidad que los términos indefinidos tendrían en las premisas silogísticas como en la casi nula noticia de que, alguna vez en la antigüedad, se desarrolló una silogística con términos indefinidos en las premisas.

\section{Palabras claves.}

Lógica aristotélica, tradición de comentarios, unidad de las obras lógicas de Boecio, influencia de Boecio en el medioevo latino, silogística, terminos indefinidos.

\section{Abstract}

In this article, the most important hypotheses concerning the doctrinal relation between Boethius' two syllogistic treatises are discussed: De syllogismo categorico and the Introductio ad syllogismos categoricos. By means of a review of both, I discard the hypothesis pointing out a strong dependence and the other hypotheses resting on a weaker dependence. I conclude that the relation between both treatises is more extrinsic than what has been believed up to here, because the second treatise is thought to be an appendage of the first one. The argument is supported on both the apparent lack of utility in using indefinite terms in the premises of a syllogism and the almost entirely absence of textual evidences that a syllogistic with indefinite terms in the premises was developed some time in ancient times.

Key Words

Aristothelic Logic, Tradition of Commentaries, Unity of the Logical Works of Boecio, His Influence in Medieval Latin, Syllogism, Undefined Terms.

30 Este trabajo ha sido posible gracias a Fondecyt 1071039. 